\title{
A CASA COMOMODELO ORGANIZACIONAL DAS NOBREZAS DE SÃO MIGUEL (AÇORES) NO SÉCULO XVIII
}

\author{
José Damião Rodrigues*
}

\begin{abstract}
RESUMO
Na Europa Moderna, o modelo central de organização dos grupos domésticos era o da casa. No arquipélago dos Açores, cujo povoamento se iniciou a partir de 1439 , a casa era também a estrutura organizadora do universo nobiliárquico local, em estreita relação com o sistema vincular. A vinculação, associada às práticas endogâmicas e consanguíneas e ao sistema de transmissão de bens por via das alianças matrimoniais, constituiu um poderoso instrumento de reprodução social das nobrezas insulares. Neste artigo, são apresentados alguns dados relativos ao modo como as nobrezas locais da ilha de São Miguel utilizaram o morgadio como instrumento de reprodução social no século XVIII e aos problemas de gestão da casa nobre.
\end{abstract}

Palavras-chave: história da família; história social; casa; nobreza local; reprodução social; morgadio; São Miguel (Açores) século XVIII.

\begin{abstract}
In Early Modern Europe, the central model of the organization of domestic groups was the household. In the archipelago of the Azores, where settlement began in 1439, household was also the reference for the organization of local nobilities, in close connection with the system of entail. The entail, in association with endogamy and consanguineous marriages and the system of property transfer by means of matrimonial alliances, was a powerful tool converted by the Azorean gentry into a means of social reproduction. In this paper, we present some data concerning the way the gentry of the island of São Miguel used the entail with that purpose in the 18th century and also the management of the noble household.
\end{abstract}

Key-words: family history; social history; household; gentry; social reproduction; entail; São Miguel (Azores) 18th century.

* Professor da Universidade dos Açores. 
Em obra colectiva recente sobre a Europa, um dos colaboradores, responsável pela análise dos modelos familiares e dos sistemas de transmissão de bens entre gerações, considerou que em Portugal coexistiam um sistema de parentela, caracterizado por uma sucessão fraccionada e pela herança igualitária, no interior do qual se podiam detectar redes de parentesco bilaterais e um sistema de casa, definido por uma sucessão única e um modelo de herança preciputário, isto é, que favorecia um herdeiro. ${ }^{1}$ Não obstante a grande complexidade que se podia observar empiricamente, marcada pela existência de adaptações do modelo "puro" às realidades locais e necessidades pontuais de famílias e indivíduos, esta tipologia pode funcionar como ponto de partida desta exposição.

A necessidade do estudo das casas e das famílias, no âmbito do poder local, tem sido colocado em destaque pela historiografia portuguesa mais recente. ${ }^{2} \mathrm{E}$ se a família era a célula-base da sociedade, o modelo organizacional dominante dos grupos familiares era, de acordo com as fontes da época, o da casa. Conceito fundamental, a sua importância resultava não apenas do facto da "economia doméstica", o "governo da casa", serem um modelo para a gestão do poder político, ${ }^{3}$ mas ainda — ou sobretudo do facto da casa não ser unicamente uma unidade residencial ou um conjunto de bens materiais, englobando também o "capital simbólico" que o nome e a história de uma determinada família transportavam. ${ }^{4}$

1 Cf. AUGUSTINS, G. Familles et parentés. In: LAMAISON, P. (Dir.). Généalogie de l'Europe de la Préhistoire au XX siècle. Paris: Hachette, 1994. p. 22-27.

2 Entre outros, cf. MACEDO, A. M. da C. Família, sociedade e estratégias de poder (17501830). A Família Jácome de Vasconcelos da Freguesia de S. Tiago da Cividade Braga, 1992. Dissertação (Mestrado em História das Populações) - Universidade do Minho; MONTEIRO, N. G. Elites locais e mobilidade social em Portugal nos finais do Antigo Regime. Análise Social, v. 32, n. 141, p. 335-368, jul./ dez. 1997. maxime p. 363-367; MONTEIRO, N. G. Poderes municipais e elites locais (séculos XVII-XIX): Estado de uma Questão. In: SEMINÁRIO INTERNACIONAL HISTÓRIA DO MUNICIPALISMO, 1., 1998, Funchal. Anais... Funchal: Centro de Estudos de História do Atlântico, Secretaria Regional do Turismo e Cultura, 1998. p. 79-89, maxime p. 83-85.

3 Cf. FRIGO, D. Il padre di famiglia. Governo della casa e governo civile nella tradizione dell "economica" tra Cinque e Seicento, "Biblioteca del Cinquecento, 29". Roma: Bulzoni Editore, 1985. p. 65-101, e, da mesma autora, "Disciplina rei familiariae: a economia como modelo administrativo de Ancien Régime". Penélope. Fazer e Desfazer a História, n. 6, p. 47-62, 1991.

4 Cf. BEUNZA, J. M. I. Comunidad, red social y élites. Un análisis de la vertebración social en el Antiguo Régimen. In: BEUNZA, J. M. I. (Dir.). Élites, poder y red social: las élites del País Vasco y Navarra en la Edad Moderna. Bilbao: Servicio Editorial, Universidad del País Vasco/EHU, 1996. p. 1350. Maxime, p. 32-33; MARTÍNEZ RUEDA, F. Poder local y oligarquías en el País Vasco: las estrategias del grupo dominante en la comunidad tradicional. In: BEUNZA, J. M. I. (Dir.). Èlites, poder y red social: las élites del País Vasco y Navarra en la Edad Moderna. Bilbao: Servicio Editorial, Universidad del País Vasco/EHU, 1996. p. 119-146. Maxime, p. 131-142. 
Com efeito, ao analisar a dimensão do parentesco e os conceitos de família que coexistiam na Europa do Antigo Regime, deparar-se com a noção de "casa" em diversos espaços socioculturais, o que demonstra, afinal, que, em termos da organização social européia, existia uma base comum. No entanto, como alertou Jean-Louis Flandrin, o conceito de "casa" não é fácil de apreender, de captar. "Casa" não significava apenas — esse seria, aliás, o seu sentido menos importante - "local de residência", "coabitação"; "casa" era um dos sinônimos de família e possuía um conteúdo que considerava não apenas aqueles que viviam numa mesma residência, mas todos quantos se encontravam ligados por laços de sangue (consangüinidade), pelo parentesco espiritual (compadrio) e por afinidade. Dito de outra maneira: a casa era não apenas domos (casa-edifício), mas também domus (casa-família), estando este último sentido intimamente associado ao conceito de linhagem e ao nome (apelido) familiar. ${ }^{6}$

Este duplo sentido de "casa" está presente na respectiva entrada no dicionário do Padre Rafael Bluteau, de começos do século XVIII. Segundo o autor, entre os múltiplos significados de "casa", podíamos encontrar quer o de "Morada de casas, edificio, em que vive huma familia com seus moveis, \& alfayas, amparada das injurias do tempo.", quer o de "Casa. Geração. Familia." " No entanto, convirá salientar que as mutações operadas no âmbito do léxico sociopolítico nos séculos XVII e XVIII e a progressiva adoção da noção de "casa" pelos grupos nobiliárquicos não eliminaram outros conceitos igualmente importantes quando se pensa na nobreza, como as de "linhagem" e "família".

No arquipélago dos Açores, cujo povoamento se iniciou entre 1439 e 1443, esta evolução do vocabulário é perceptível quando são analisadas

5 Cf. FLANDRIN, J.-L. Famílias. Parentesco, casa e sexualidade na sociedade antiga, Lisboa: Estampa, 1992. p. 19 (edição original: 1976; edição revista: 1984).

6 Cf. COLLOMP, A. La Maison du Père. Famille et village en Haute-Provence aux XVIIe et XVIIIe siècles. Paris: PUF, 1983. p. 81-82.

7 Cf. BLUTEAU, R. Vocabulario portuguez e latino. Coimbra: Real Colégio das Artes da Companhia de Jesus, 1712. v. 2. p. 172-175, Maxime, p. 172 e 174.

8 Sobre esta questão, ver MONTEIRO, N. G. Casa e linhagem: o vocabulário aristocrático em Portugal nos séculos XVII e XVIII. Penélope. Fazer e Desfazer a História, n. 12, p. 43-63, 1993 e, do mesmo autor, O crepúsculo dos grandes. A casa e o património da aristocracia em Portugal (1750-1832). Análise Social, Lisboa, p. 79-97, 1998. 
algumas das obras mais marcantes da historiografia local. Na crónica tardo-quinhentista da autoria do padre micaelense Gaspar Frutuoso (15221591), intitulada Saudades da Terra, é ainda predominante uma apresentação das genealogias das principais famílias ancorada numa organização linhagística. Os conceitos norteadores do autor parecem ser os de "família", "geração" e "linhagem", como se pode ler quase ao abrir o Livro Quarto, dedicado à ilha de São Miguel:

Porque, posto que seja condição geral de todas as gentes, por darem antigos e ilustres princípios a sua linhagem, sempre fabularem coisas, a que a antiguidade, não testemunha [...]; assim como não deixei de contar a certeza do que soube dos ilustres capitães da ilha da Madeira e Santa Maria, e de seus moradores, assim também não deixarei de dizer (pois falo antre vivos que, se não viram, ouviram) o que ouvi afirmar por muito certo a alguns antigos, dignos de fé desta ilha de S. Miguel, do que sabiam da origem e feitos de seus ilustres capitães, que dos da ilha da Madeira por linha masculina descendem. ${ }^{9}$

E, mais adiante, referindo-se a João de Barros e a Marco Túlio, explicava, acerca deste último, que "uma das coisas que o pôs em a dignidade consular, que era a maior que naquele tempo havia, foi ter grande conhecimento das linhagens, famílias, das propriedades e de outros negócios públicos do povo romano," para depois informar que iria tratar da "progénia dos antigos descobridores e povoadores desta ilha, começando na geração e apelidos dos Velhos, donde descende o primeiro Capitão dela." 10

Este tipo de exposição, que apresentava as famílias nobres segundo as linhas de descendência, está igualmente presente nas obras de dois padres naturais da ilha Terceira, Manuel Luís Maldonado (1645-1711) ${ }^{11} \mathrm{e}$

9 Cf. FRUTUOSO, G. Livro quarto das saudades da Terra. 2. ed. Ponta Delgada: Instituto Cultural de Ponta Delgada, 1977. v. 1, p. 4.

10 Ibid., p. 25-26.

11 Cf. MALDONADO, Pe. L. M. Fenix Angrence. Transcrição e notas de Helder Fernando Parreira de Sousa Lima. Angra do Heroísmo: Instituto Histórico da Ilha Terceira, 1997. p. 16-91. 3. v. Nesta obra, o autor apresenta as genealogias das famílias dos capitães de Angra e da Praia e as das "famílias nobres e honradas" que povoaram a Ilha Terceira, organizadas segundo o modelo linhagístico. 
António Cordeiro (1640-1722), ${ }^{12}$ concluídas em inícios do século XVIII. Assumindo a sua dívida para com Gaspar Frutuoso, António Cordeiro desenvolveu as genealogias das principais famílias (ou apelidos ${ }^{13}$ ) das ilhas açorianas com base no conceito linhagístico ("linha"14 ). Todavia, se as noções de "família" e "linhagem" parecem predominar em termos de exposição, ${ }^{15}$ no texto deste jesuíta terceirense verifica-se que o conceito de "casa" está subjacente ao discurso e que, em mais de uma passagem, o autor apresenta a "casa" como configurando o modelo organizacional da nobreza, em geral, e da micaelense, em particular. ${ }^{16}$

A generalização do modelo da "casa" ao arquipélago, visível no discurso do padre António Cordeiro, também pode ser detectada em outras fontes da época. Em 1659, Cosme Ferreira de Brum, cavaleiro professo da Ordem de Cristo, natural e morador em Lisboa, apresentou uma justificação relativa aos Bruns. De acordo com o que declarou, Guilherme de Brum viera da Flandres para Portugal no tempo de D. João II, passando à ilha da Madeira, onde se casara com Violante Vaz Ferreira Pimentel; um filho de ambos, António de Brum, o Velho, casou com Bárbara da Silveira e instituiu um morgadio nas ilhas de São Miguel, Terceira e Faial, sendo a cabeça e assento na de São Miguel, "onde sempre viveram os Senhores desta casa."17

A noção de "casa", tal como a encontramos nesta justificação, podia também ser encontrada na crónica de frei Diogo das Chagas (c. 1584-c. 1661),${ }^{18}$ natural da Ilha das Flores e contemporâneo de Cosme Ferreira de

12 Cf. CORDEIRO, Pe. A. Historia insulana das ilhas a Portugal sugeytas no Oceano Occidental. Angra do Heroísmo: Secretaria Regional da Educação e Cultura, 1981. (edição fac-similada da edição princeps, de 1717).

13 Ibid., p. 194, 197 (O appellido de sua nobre varonia), 198, 203 (O appellido de Faria) e 206.

14 Ibid., p. 187, 192, 194, 195 e 201.

15 Notemos, de passagem, que em obra coeva de Padre Antonio Cordeiro, $O$ Vocabulario portuguez e latino, do Padre Rafael Bluteau, este autor apresentou dois significados para "família", fazendo coincidir o conceito de "família nobre" com o de "linhagem". Cf. BLUTEAU, op. cit., p. 28. v. 4.

16 Cf. CORDEIRO, op. cit., p. 172, 175, 180 (As mais das casas nobres destas duas Ilhas de Santa Maria \& São Miguel), 186, 195, 200 (A grande casa do pay), 201 (Casas titulares) e 206-207 (Das principais \& ricas casas de Ponta Delgada).

17 Cf. BIBLIOTECA PÚBLICA E ARQUIVO REGIONAL DE PONTA DELGADA (BPARPD); FUNDO ERNESTO DO CANTO (FEC), MANUSCRITOS (Mss), 26, fls. 106-110 v. Justificação de Cosme Ferreira de Brum Lisboa no anno de 1659. Maxime, fl. 107, para a citação.

18 Cf. CHAGAS, Fr. D. das. Espelho cristalino em jardim de várias flores. Direção e prefácio de Artur Teodoro de Matos, colaboração de Avelino de Freitas de Meneses e Vítor Luís Gaspar Rodrigues. Angra do Heroísmo: Secretaria Regional da Educação e Cultura, 1989. 
Brum. Contudo, seria somente no final do século XVIII, com o morgado João de Arruda Botelho da Câmara, que aquele conceito iria ser colocado no centro do discurso nobiliárquico local. João de Arruda Botelho da Câmara (1774-1845), morgado, genealogista e membro da governança da cidade de Ponta Delgada, a "cabeça" da ilha de São Miguel, ${ }^{19}$ iniciou em fins de setecentos a elaboração de um texto onde organizou os elementos que foi recolhendo sobre genealogias e administrações de vínculos. Com uma aguda cultura genealógica e consciente da importância de deter um conhecimento seguro acerca das instituições vinculares, afirmou, ao iniciar o seu texto:

com grande despeza mandei lavrar dezasseis pedras de quatro palmos quadrados, aonde fiz gravar em letra redonda os sucessos mais notáveis da história, e descobrimento destas ilhas dos Açores, e Madeira, e me vi obrigado a escolher palavras de menos letras, e breves para uma pedra não depender da outra senão na época, e bem conheço que foi grande afouteza em mim o deliberar-me a compôr, e arranjar as tais inscrições, e que serei taxado por tratar nelas da fundação dos muitos vínculos, que instituirão os meus ascendentes, e parentes Arrudas, que estão espalhados pelas casas mais ricas desta Ilha, e dos que eu possuo, e dos serviços que eles fizerão ao Rei, à Religião, e à Pátria, e da razão por que me pertencem por legístima descendência. ${ }^{20}$

Se, como refere Nuno Gonçalo Monteiro, o conceito de "casa" era diferente do de "linhagem" 21 e um "sistema de casas"22 era, no limite,

19 Sobre esta questão, ver RODRIGUES, J. D. São Miguel no século XVIII: casa, família e mecanismos de poder. Ponta Delgada, 2001. Tese (Doutorado em História Moderna) - Universidade dos Açores. v. 1, p. 235-238 (policopiado).

20 Cf. CÂMARA, M. J. de A. B. da. Instituições vinculares e notas genealógicas. Leitura diplomática e tratamento de texto de Nuno Álvares Pereira. Ponta Delgada: Instituto Cultural de Ponta Delgada, 1995. p. 2.

21 Cf. MONTEIRO, Casa e..., oq. cit., p. 43-63. Maxime p. 45; MONTEIRO, O crepúsculo..., op. cit., p. 82 .

22 O conceito de "sistema de casas" foi retirado de DEROUET, B. Dot et héritage: les enjeux de la chronologie de la transmission. In:___. L'histoire grande ouverte. Hommages à Emmanuel Le Roy Ladurie. Réunis sous la direction d'André Burguière, Joseph Goy et Marie-Jeanne Tits-Dieuaide. Paris: Fayard, 1997. p. 284-292. 
anti-linhagístico - a reprodução da casa era o essencial, independentemente de quem a reproduzia -, em João de Arruda Botelho da Câmara deparamos com o recurso ao estudo das linhagens e a apresentação das linhas masculinas - "a linha masculina é a principal, e única em cada morgado", afirma ${ }^{23}$ - e femininas em prol de um objectivo: produzir um objecto de consulta onde perdurasse a memória da instituição de morgadios e capelas e fossem registadas as casas vinculares de São Miguel, com as respectivas administrações. ${ }^{24}$ É, de resto, a noção de "casa vincular" (ou "casa vinculada"), associando casa, nome e vínculo, que preside à organização da obra de João de Arruda Botelho da Câmara ${ }^{25}$ e que seria preservada por Ernesto do Canto (1831-1900), que continuou e anotou os apontamentos do morgado João de Arruda. ${ }^{26}$

Colocadas à disposição de parentes e amigos para consulta, as notas de João de Arruda viriam a constituir-se como um poderoso mecanismo de produção identitária. Individual, antes de mais: a do autor, que mobilizou em seu favor uma cronologia dos eventos familiares (baptismos, casamentos, óbitos, testamentos, instituições de vínculos) e inscreveu assim o seu nome no fio da memória, num continuum temporal em que surgia como o elo entre as gerações passadas e as futuras, ligadas pelo sangue e pelo

23 Cf. CÂMARA, op. cit., p. 2. Esta valorização da linha masculina, que traduz a idéia de que é o filho varão que carrega em si a continuidade do pai, está de acordo com os valores dominantes no Antigo Regime, que atribuíam à mulher uma identidade negativa e um papel secundário no quadro da família. Como sintetizou Olwen Hufton: "Independentemente das suas origens sociais, a partir do momento em que nascesse de um casamento legítimo, qualquer rapariga passava a ser definida pela sua relação com um homem. O pai e depois o marido eram legalmente responsáveis por ela, sendo-lhe reco-mendado que a ambos honrasse e obedecesse." Cf. HUFTON, O. Mulheres, trabalho e família. In: DUBY, G.; PERROT, M. (Dir.). História das mulheres no Ocidente: do Renascimento à Idade Moderna. Sob a direção de Natalie Zemon Davis e Arlette Farge. Porto: Afrontamento, 1994. v. 3, p. 23. (Edição original: 1991).

24 Sobre a importância da memória genealógica e a construção de genealogias, vejam-se, para a Florença renascentista, os estudos de KLAPISCH-ZUBER, C. L'invention du passé familial e Le travail généalogique. In: ___ La maison et le nom. Stratégies et rituels dans l'Italie de la Renaissance. "Civilisations et sociétés, 81" Paris: École des Hautes Études en Sciences Sociales, 1990. (Civilisations et sociétés, 81) p. $19-35$ e 37-58, respectivamente. Acerca da centralidade dos laços verticais e do peso das linhagens na construção de histórias de famílias, concluiu a autora: "Prééminence qui modèle les comportements quotidiens des Toscans, affecte la conscience de leur identité, et peuple d'ancêtres leur mémoire de la casa. Qu'il les ressuscite en guise de 'passe-temps' ou sous l'urgence d'une nécessité plus grande, c'est en eux que l'individu voit les meilleurs garants de la place qui lui revient dans la société et ses intercesseurs privilégiés en ce bas monde." (Cf. KLAPISCH-ZUBER, Le travail..., op. cit., p. 37-58. Maxime, p. 58) São palavras que, em nosso entender, aplicam-se sem dificuldade ao Morgado João de Arruda Botelho da Câmara.

25 Cf. CÂMARA, op. cit., p. 3, 10, 14, 23 e 158.

26 Ibid., p. 144 e 147. 
nome de família. ${ }^{27}$ Colectiva, depois: familiar, na medida em que a organização por casas vinculares introduzia uma arrumação por famílias, que permitia a cada um dos respectivos membros reconhecer-se no contexto da exposição das diversas "constelações de linhagens"; ${ }^{28}$ e grupal, pois o trabalho empreendido pelo morgado João de Arruda apresentava-se como um painel onde figuravam as principais casas nobres da ilha, contribuindo, desse modo, para a construção de uma identidade nobiliárquica.

Nesse sentido, a obra do morgado João de Arruda, não sendo exactamente uma genealogia, cumpria a função social das mesmas: a produção de uma identidade colectiva (familiar e de grupo). Todavia, esta afirmação identitária era também uma selecção e, por isso mesmo, um mecanismo de diferenciação social dentro do corpo nobiliárquico micaelense. Ao incluir apenas as casas vinculares e os administradores de vínculos de São Miguel, no que foi seguido por Ernesto do Canto, João de Arruda introduziu uma clivagem no interior das famílias nobres: de um lado, estavam aquelas que, por via masculina ou feminina, administravam capelas e morgadios, desde a primeira fundação vincular na ilha, em 1493; do outro, as que permaneciam no exterior do sistema vincular e foram excluídas do registo. O texto do morgado João de Arruda é, neste aspecto, também um produtor de diferenças, ao instaurar uma separação entre as casas que configuravam a "elite da elite" micaelense e as demais, que não podiam concorrer com as primeiras nem em termos de "pedigree genealógico", ${ }^{29}$ nem em termos de património.

A casa, "entendida como um conjunto coerente de bens simbólicos e materiais a cuja reprodução alargada estavam obrigados todos os que nela nasciam ou dela dependiam", ${ }^{30}$ consubstanciava-se, pois, como a estrutura organizadora do universo nobiliárquico nos Açores no final do An-

27 Cf. CANDAU, J. Mémoire et Identité. Sociologie d'aujourd'hui. Paris: PUF, 1998. p. 131-136.

28 A imagem é de GUIGNET, P. Le pouvoir dans la ville au XVIIIe siècle: pratiques politiques, notabilité et éthique sociale de part et d'autre de la frontière franco-belge. Paris: École des Hautes Études en Sciences Sociales, 1990. p. 317. (Civilisation et Sociétés, 80).

29 A expressão é de SOBRAL, J. M. Trajectos: o presente e o passado na vida de uma freguesia da beira. Análise Social, Lisboa, p. 211, 1999.

30 Cf. MONTEIRO, O crepúsculo..., op. cit., p. 91. 
tigo Regime, em estreita relação com o sistema vincular. ${ }^{31}$ Esta íntima associação entre casa e morgadio, conforme acabamos de expor, foi definida de forma lapidar pelo morgado João de Arruda, que entendeu claramente que a preservação do status individual e familiar das nobrezas locais de São Miguel passava pela necessidade de conservarem o suporte material das casas, os vínculos e pela definição de quais as estratégias reprodutivas mais adequadas em cada momento, ${ }^{32}$ como meio de evitar cair na pobreza. ${ }^{33}$

Era em função da conservação da casa que se estabeleciam as alianças matrimoniais, quer aquelas que tinham lugar entre diferentes famílias, não aparentadas entre si, quer as que ocorriam dentro do círculo estreito da parentela, entendida aqui simultaneamente como "esquema operativo" e como "rede de parentesco". ${ }^{34}$ Claro que a conservação da casa significava, para além de preservar o património familiar, manter o estatuto social da família, garantir a transmissão do "capital simbólico", que também podia ser designado por "herança imaterial" e consistia, afinal, no prestígio familiar. Honra e prestígio estão intimamente articulados nas sociedades tradicionais, sendo o prestígio um "elemento estructural, integrador y estabilizador del orden social del Antiguo Régimen, pues el ostentar una determinada calidad o categoría de vida y asumir sus normas de sociabilidad es algo que

31 A própria legislação régia estabelecia essa associação. Cf. ORDENAÇÕES filipinas. Edição fac-similada da edição de Cândido Mendes de Almeida, Rio de Janeiro, 1870. Lisboa: Fundação Calouste Gulbenkian, 1985, livro 4, título C, "Per que ordem se succederá nos Morgados e bens vinculados", p. 990993, onde o texto do legislador menciona, mais de uma vez e sempre em articulação, casas e morgadios ("casas e Morgados"). Sobre esta questão e, para Guimarães, nos finais do Antigo Regime, ver MARINHO, J. da S. Construction d'un gouvernement municipal. Élites, élections et pouvoir à Guimarães entre absolutisme et libéralisme (1753-1834). Braga: Universidade do Minho, 2000. p. 238-243.

32 As condicionantes da política matrimonial de uma família estão bem patentes numa passagem de frei Diogo das Chagas. A necessidade das famílias adotarem uma estratégia reprodutiva que jogasse com o equilíbrio entre o número, o sexo dos filhos e o seu património transparece na situação das filhas do capitão Rafael Cardoso de Novais, da governança de Ponta Delgada (foi vereador em 1637 e 1642). Delas diz o cronista que "ambas estam em casa de seus Pays, moças de pouca idade de boas partes e musicas excellentes pera freiras mas como os pays não tem outros filhos, nem esperança de os ter, por conseruar a caza as querem cazar." Cf. CHAGAS, op. cit., p. 209. Ou seja, o destino inicial das moças, o claustro, foi alterado, em função de um objetivo mais importante, a reprodução da família, face à ausência de varões.

33 Cf. CÂMARA, op. cit., p. 2, 9 e 14.

34 Cf. CAMPS, J. B. Casa y familia. Parentesco y reproducción doméstica en Formentera. Palma de Mallorca: Institut d'Estudis Baleàris, 1986. p. 121-170. 
se obtiene fundamentalmente como resultado de lazos de sangre y alianzas matrimoniales." 35

O ideal da casa estava igualmente patente, talvez até com maior clareza, nos documentos de instituição vincular. Com efeito, nos textos de fundação de um vínculo (morgadio ou capela), vários foram os instituidores, clérigos ou leigos, que definiram cláusulas relativas à sua casa ou à de parentes. ${ }^{36}$ No testamento do padre Manuel Pires de Sousa, redigido na Ribeira Seca, a 17 de Setembro de 1705, um primeiro vínculo foi legado ao sobrinho, João de Sousa de Matos, com a obrigação deste e seus sucessores celebrarem anualmente uma capela de missas perpétuas. Por morte do sobrinho, os bens ficariam ao filho mais velho ou, não o havendo, à filha mais velha. Caso o sobrinho tivesse algum filho que quisesse ser clérigo, poderia fazer património com os ditos bens e o referido encargo "e por morte do clerigo tornarão os dittos bens ao Irmão ou Irmãa do clerigo se ouuer para que sempre andem em Caza do ditto seu sobrinho e faltando descendencia do ditto seu sobrinho hirá ao parente mais chegado delle testador com as mesmas obrigaçoens e condiçoens." ${ }^{37}$

Também em instrumento de doação post-mortem e entre vivos, feito na vila da Ribeira Grande, a 10 de Janeiro de 1728, no qual participaram como doadores o capitão Jerónimo Tavares de Arruda, membro de uma importante família da oligarquia local, e sua mulher, D. Maria Leite - era filha do tenente-general Manuel de Borba Gato -, e como doado o filho, Francisco de Arruda Leite, a noção de casa está presente e uma estratégia reprodutiva é bem visível. ${ }^{38}$ Nesse documento, os doadores declararam que o filho sempre lhes obedecera, nunca indo contra a vontade paterna e, ainda, que na sua casa não havia bens de sucessão "por serem os muitos que nella há todos partiueis." Desse modo, "e por dezejarem mujto aumentar e perpeticar [sic] a

35 Cf. CHACÓN JIMÉNEZ, F.; HERNÁNDEZ FRANCO, J. Introducción. In: (Eds.). Poder, familia y consanguinidad en la España del Antiguo Régimen. Historia, Ideas y Textos, 20. Barcelona: Anthropos, 1992. p. 8.

36 Cf. GIMENO SANFELIU, M. J. Patrimonio, parentesco y poder (Castelló, siglos XVI-XIX). Castelló de la Plana: Publicacions de la Universitat Jaume I, 1998. (Biblioteca de les aules, 7), p. 139.

37 Cf. ARQUIVO DA CÂMARA DA LAGOA. Legados Pios. Administração do vínculo do padre Manuel Pires de Sousa, m. sem n., n. 135, fls. 28-34 v. Maxime, fl. 30, para a citação (grifo nosso).

38 PROVEDORIA DOS RESÍDUOS E CAPELAS DE PONTA DELGADA - BPARPD. Legados Pios. Testamento do capitão Jerónimo Tavares de Arruda, Ribeira Grande, 2 abr. 1737, m. 68, n. 599. Maxime, fls. 7-18. Instrumento de doação post-mortem e entre vivos, Ribeira Grande, 10 jan. 1728. 
Caza do dito dotado seu filho e nelle se conseruar o esplendor de sua familia," dotaram-no com as respectivas terças, constituídas por 2 moios e 9 alqueires de terra, sitos no Morro de Cima, no Cerrado da Cancela. ${ }^{39}$

Delineada a reprodução da casa, havia que mantê-la e, para tal, era imperioso que a sua administração fosse cuidada, precavendo o futuro. A tratadística da época, de resto, desenvolveu toda uma teoria relativamente à “economia da casa" e sua administração. ${ }^{40}$ Estes princípios estão plasmados num atestado abonatório passado a favor de Francisco do Canto de Castro Pacheco, da ilha Terceira, em finais de 1806. De acordo com o texto do atestado, Francisco do Canto de Castro Pacheco "he geralmente reputado nesta Ilha, como o exemplar de todos os Administradores della, pela sabia, e prudente ecconomia, com que administra hua boa Caza, composta de varios vinculos." ${ }^{41}$

Como se organizava a administração de cada casa ou, pelo menos, das principais casas de São Miguel no Antigo Regime? Este é um campo ainda por explorar no âmbito da historiografia local. Entre as dificuldades com que se deparam os historiadores na análise desta importante vertente da economia nobiliárquica, a ausência de cartórios das casas, com livros de tombo e de contabilidade, é, de um modo geral, o maior óbice à compreensão do funcionamento da economia senhorial micaelense. ${ }^{42}$ À imagem do que fez, no fim de setecentos, o morgado João de Arruda, os cabeças de cada uma das grandes casas de São Miguel deveriam ter um registo dos vínculos administrados, dos foros e das rendas auferidos e dos rendeiros, bem como traslados de testamentos, ${ }^{43}$ certidões, pareceres jurídicos, reci-

39 PROVEDORIA..., op. cit., fl. 9 (grifo nosso).

40 Cf. ATIENZA HERNÁNDEZ, I. Teoría y administración de la casa, linaje, familia extensa, ciclo vital y aristocracia en Castilla (s. XVI-XIX). In: CHACÓN JIMÉNEZ, F.; HERNÁNDEZ FRANCO, J.; PEÑAFIEL RAMÓN, A. (Eds.). Familia, grupos sociales y mujer en España (siglo XV-XIX). Murcia: Universidad de Murcia, 1991. p. 13-47.

41 Cf. BPARPD; FEC; Mss. 15. Documentos da casa de Miguel do Canto e Castro. Praia, 5 dez. 1806 , doc. 371 , v. 13

42 Nesse sentido, a organização em curso do Arquivo Brum da Silveira, depositado nos Serviços de Documentação da Universidade dos Açores, e dos arquivos de família (Costa Chaves e Melo, Dias do Canto e Medeiros) incluídos no Fundo Ernesto do Canto, depositado na Biblioteca Pública e Arquivo Regional de Ponta Delgada, poderão representar um ponto de partida para uma investigação aprofundada dessas questões.

43 O livro do tombo da casa Soares de Sousa (ou Soares de Sousa Albergaria) constitui, neste particular, um bom exemplo. Em 1704, na sequência de dúvidas acerca do direito de posse de diversas administrações vinculares instituídas nos séculos anteriores, o capitão Antônio Soares de Sousa Ferreira, fidalgo da Casa Real e cidadão de Ponta Delgada, mandou trasladar num livro vários testamentos, folhas de partilha e sentenças em públicas formas, por dois tabeliães. Além de querer preservar o conteúdo desses 
bos etc. Só assim poderiam justificar a posse de certos bens e organizar a aplicação dos rendimentos da casa, relativamente às despesas da mesma. ${ }^{44}$ Em 1781, José de Medeiros da Costa e Albuquerque, de uma das mais nobres famílias de Ponta Delgada, informava, em representação dirigida a D. Maria I, que na ilha de São Miguel existiam vários morgados: na cidade, podiam-se contar mais de vinte casas com rendas entre 3.000 e 13.000 cruzados, além de outras de menores rendimentos; por seu lado, as vilas contavam também com casas que caíam em ambas as categorias. Todas, porém, no dizer do autor, tinham problemas de capital, "o que rezulta da má ordem economica." ${ }^{45}$

A coroa, atenta à manutenção da ordem social e defesa do estado nobiliárquico, zelava pela conservação das casas nobres e, em casos extremos de má gestão ou de endividamento excessivo, podia nomear uma administração judicial para uma determinada casa ${ }^{46}$ Em São Miguel, o caso mais notório foi o da casa Faria e Maia, durante o tempo em que José Inácio Machado de Faria e Maia foi o chefe da mesma.

Os problemas desta casa nasceram na primeira metade de setecentos. Francisco Machado de Faria e Maia era o cabeça de uma das casas mais ilustres e poderosas de São Miguel e, ao falecer, a 5 de Maio de $1730,{ }^{47}$ deixou uma fortuna avaliada em 15.061.212 réis. No entanto, as dívidas acumuladas minavam o património familiar, ascendendo a 12.378 .886 réis. Aba-

documentos, devido à sua antiguidade e "má letra" (fl. 7), pretendia igualmente que não houvesse qualquer dúvida quanto ao seu direito à posse, por sucessão, dos citados vínculos. Uma cópia deste códice pode ser consultada na Biblioteca Nacional (Lisboa), no Arquivo de Família dos Botelhos de Nossa Senhora da Vida. O original, na posse dos herdeiros do Dr. Manuel Monteiro Velho Arruda, foi lido e transcrito paleograficamente pelo Dr. Pedro Pacheco de Medeiros, herdeiro, técnico superior da Biblioteca Pública e Arquivo Regional de Ponta Delgada.

44 Cf. BPARPD; FEC; Mss. 27, 28 e 35, passim (livros dos Arquivos Costa Chaves e Melo e Dias do Canto e Medeiros, com documentação vária dos séculos XVI a XIX); BPARPD. Fundo José do Canto, 53, Rol das rendas do morgado Tomás Francisco Brum da Silveira Porras; ARQUIVO BRUM DA SILVEIRA. Livro de registo das rendas do morgado Tomás Francisco Brum da Silveira Porras. Serviços de Documentação da Universidade dos Açores.

45 Cf. RILEY, C. G. As luzes escondidas da modernidade em S. Miguel (uma proposta de itinerário retrospectivo). In: CONGRESSO 1. ${ }^{\circ}$ CENTENÁRIO DA AUTONOMIA DOS AÇORES, COLECÇÃO AUTONOMIA, 19. Ponta Delgada. Actas... Ponta Delgada: Jornal de Cultura, 1995. p. 159-206. v. 1. Maxime, p. 204.

46 Sobre esta questão, ver MONTEIRO, O crepúsculo..., op. cit., p. 412-416.

47 Cf. BPARPD. Óbitos. Registo Paroquial, Ponta Delgada, São Sebastião, livro sem n. (1709-1731), fls. 237-237 v. 
tidos os valores das dívidas, dos legados do defunto (93.280 réis) e dos custos dos autos (15.000 réis), a fazenda líquida ficou reduzida a 2.574.046 réis. Quais as causas de um tão elevado endividamento? Sabemos que o capitão Francisco Machado de Faria e Maia levou a cabo diversas obras de conservação e de melhoramento na quinta da Rocha Quebrada, na Atalhada, termo rural da vila da Lagoa; na quinta do Cabouco, no mesmo conceIho; e nas suas casas da cidade, a "da praça", fronteira à Igreja Matriz de Ponta Delgada, e a "do contador", ou seja, situada na Rua do Contador, a famosa casa da Arquinha. Estas obras de beneficiação foram avaliadas em 1.100 .000 réis e integravam-se num tipo de investimentos que era comum entre as nobrezas européias, visando melhorar o exterior e o interior das suas casas de morada. ${ }^{48}$ Porém, o montante declarado para as despesas de melhoras estão ainda longe do valor total das dívidas. Teria parte desse valor que foi herdado do pai ou o investimento em gastos sumptuários por parte de Francisco Machado de Faria e Maia exigiu o recurso ao crédito? Talvez radiquem aqui os problemas que, décadas mais tarde, atormentariam a gestão desta casa e conduziriam a coroa a nomear uma administração judicial para a mesma.

Com efeito, o rei D. José acudiria à desordem em que se achava a casa de José Inácio Machado de Faria e Maia, "huma das principaes da Ilha de S. Miguel," nomeando para a dita uma administração judicial. Por resolução de 8 de outubro de 1781, fora devolvida ao cabeça da casa a administração da mesma e dos respectivos bens, mas, segundo constatavam as autoridades, "nao [sic] só se não tem emendado dos vicios, que o inhabilitarão para a sobredita administração, mas que se acha habitualmente em <estado> mais deploravel que // que o precedente." Desse modo, por decisão superior, a administração ficou a cargo do provedor da Fazenda Real e de "hum Negoceante de probidade e abonado," assegurando-se por esta via os alimentos à filha e sucessora, D. Helena Vitória Máxima da Câmara. ${ }^{49}$

Este terá sido, no entanto, um exemplo isolado. De um modo geral, as casas nobres micaelenses, quer as de maior lustro e riqueza, quer as de

48 Cf. SANZ, J. A. C. Rentas y patrimonios de la nobleza valenciana en el siglo XVIII. Historia, Madrid, p. 268, 1995.

49 Cf. ARQUIVO HISTÓRICO ULTRAMARINO - AHU. Açores, cx. 22, doc. 43, 30 maio 1792. 
pequena dimensão, procuraram organizar as respectivas administrações e souberam cuidar da sua reprodução. Assim se compreende como puderam sobreviver às convulsões do final do Antigo Regime. No trânsito para a contemporaneidade, encontramos em São Miguel, ao começar o século XIX, a permanência das famílias das elites locais no poder, seja no municipal ou no eclesiástico. Com maior ou menor projecção social e dispondo de um património mais ou menos importante, consoante o espaço concelho considerado, podemos, no entanto, concluir que a sua continuidade à frente dos destinos das comunidades mergulhava as raízes na estrutura jurídica da sociedade estamental - que relevava o privilégio e a honra - e no leque de estratégias de reprodução social adoptadas.

Estas, praticadas com graus de sucesso variáveis, devido a condicionalismos de natureza diversa - a demografia familiar, o capital disponível, o estatuto familiar, o concelho de origem, entre outros factores -, não divergiram muito de uma matriz em que as relações de parentesco detinham uma função central e que englobava a articulação entre endogamia e consangüinidade, práticas de exclusão do mercado matrimonial, vinculação de bens e integração em redes relacionais. As alianças matrimoniais e a prática da consangüinidade contribuíram para concentrar num círculo mais estreito a propriedade vinculada: embora de forma desigual, os 522 vínculos apresentados pelo morgado João de Arruda e por Ernesto do Canto, que corresponderiam a cerca de quarenta por cento do total de institutos vinculares $(42,1 \%),{ }^{50}$ concentravam-se em 57 casas, muitas delas aparentadas entre si. ${ }^{51} \mathrm{~A}$ vinculação, associada às práticas endogâmicas e consanguíneas e ao sistema de transmissão de bens por via das alianças matrimoniais, nas quais o dote desempenhava um papel central, constituiu um poderoso instrumento de reprodução social das nobrezas micaelenses, impedindo que o patrimônio concentrado nas casas vinculares se fragmentasse e reduzisse o

50 Foi considerado como total, aqui, o valor de 1.241 vínculos por esse autor inventariado. Cf. RODRIGUES, op. cit., p. 699, quadro 77, v. 2.

51 Esta parecia ser uma situação comum num contexto de "sistema de casas". Cf. AUGUSTINS, G. La perpétuation des groupes domestiques. Un essai de formalisation, L'Homme. Revue Française d'Anthropologie, n. 148, p. 15-45, out./dez. 1998. Maxime, p. 39. Para uma comparação com o caso espanhol, caracterizado pela forte concentração de vínculos no século XVIII, veja-se BERNAL, A. M. Antiguo régimen y transformación social. In: AAVV. Antiguo régimen y liberalismo. Homenaje a Miguel Artola. Madrid: Ediciones de la Universidad Autónoma de Madrid, 1994. t. 1, p. 69-86. Maxime, p. 72. 
suporte material do poder dos grupos oligárquicos. As casas mais importantes souberam adaptar-se aos novos tempos com tal sucesso, que, ao fornecerem uma sólida base de apoio à causa liberal, após 1820, veriam a sua adesão ao novo regime ser recompensada com um título nobiliárquico.

\section{Referências}

BPARPD; FEC; Mss. 15. Documentos da casa de Miguel do Canto e Castro. Praia, 5 dez. 1806, doc. 371, v. 13.

ARQUIVO BRUM DA SILVEIRA. Livro de registo das rendas do morgado Tomás Francisco Brum da Silveira Porras. Serviços de Documentação da Universidade dos Açores.

ARQUIVO DA CÂMARA DA LAGOA. Legados Pios. Administração do vínculo do padre Manuel Pires de Sousa, m. sem n., n. 135, fls. 28-34 v. Maxime, fl. 30, para a citação (grifo nosso).

ARQUIVO HISTÓRICO ULTRAMARINO - AHU. Açores, cx. 22, doc. 43, 30 maio 1792.

ATIENZA HERNÁNDEZ, I. Teoría y administración de la casa, linaje, familia extensa, ciclo vital y aristocracia en Castilla (S. XVI-XIX). In: CHACÓN JIMÉNEZ, F.; HERNÁNDEZ FRANCO, J.; PEÑAFIEL RAMÓN, A. (Eds.). Familia, grupos sociales y mujer en España (siglo XV-XIX). Murcia: Universidad de Murcia, 1991. p. 13-47.

AUGUSTINS, G. Familles et parentés. In: LAMAISON, P. (Dir.). Généalogie de l'Europe de la Préhistoire au XX siècle. Paris: Hachette, 1994. p. 22-27.

La perpétuation des groupes domestiques. Un essai de formalisation, L'Homme. Revue française d'anthropologie, n. 148, p. 15-45, out./dez. 1998. Maxime, p. 39.

BERNAL, A. M. Antiguo Régimen y transformación social. In: AAVV. Antiguo Régimen y liberalismo. Homenaje a Miguel Artola. Madrid: Ediciones de la Universidad Autónoma de Madrid, 1994. p. 69-86. t. 1. Maxime, p. 72.

BEUNZA, J. M. I. Comunidad, red social y élites. Un análisis de la vertebración social en el Antiguo Régimen. In: .(Dir.). Elites, poder y red social: las élites del País Vasco y Navarra en la Edad Moderna. Bilbao: Servicio Editorial, Universidad del País Vasco/EHU, 1996. p. 13-50. Maxime, p. 32-33. 
BIBLIOTECA PÚBLICA E ARQUIVO REGIONAL DE PONTA DELGADA (BPARPD); FUNDO ERNESTO DO CANTO (FEC), MANUSCRITOS (Mss), 26, fls. 106-110 v. Justificação de Cosme Ferreira de Brum Lisboa no anno de 1659. Maxime, fl. 107, para a citação.

BLUTEAU, R. Vocabulario portuguez e latino. Coimbra: Real Colégio das Artes da Companhia de Jesus, 1712. p. 172-175, v. 2. Maxime, p. 172 e 174.

BPARPD. Óbitos. Registo Paroquial, Ponta Delgada, São Sebastião, livro sem n. (1709-1731), fls. 237-237 v.

CÂMARA, M. J. de A. B. da. Instituições vinculares e notas genealógicas: leitura diplomática e tratamento de texto de Nuno Álvares Pereira. Ponta Delgada: Instituto Cultural de Ponta Delgada, 1995. p. 2.

CAMPS, J. B. Casa y familia. Parentesco y reproducción doméstica en Formentera. Palma de Mallorca: Institut d'Estudis Baleàris, 1986, p. 121-170.

CANDAU, J. Mémoire et Identité: Sociologie d'aujourd'hui. Paris: PUF, 1998. p. 131-136.

CHACÓN JIMÉNEZ, F.; HERNÁNDEZ FRANCO, J. Introducción. In:

(Eds.). Poder, familia y consanguinidad en la España del Antiguo Régimen. Historia, Ideas y Textos, 20. Barcelona: Anthropos, 1992. p. 8.

CHAGAS, Fr. D. das. Espelho cristalino em jardim de várias flores. Direção e prefácio de Artur Teodoro de Matos, colaboração de Avelino de Freitas de Meneses e Vítor Luís Gaspar Rodrigues. Angra do Heroísmo: Secretaria Regional da Educação e Cultura, 1989.

COLLOMP, A. La Maison du Père. Famille et village en Haute-Provence aux XVII et XVIII' siècles. Paris: PUF, 1983. p. 81-82.

CORDEIRO, Pe. A. Historia insulana das ilhas a Portugal sugeytas no Oceano Occidental. Angra do Heroísmo: Secretaria Regional da Educação e Cultura, 1981. (edição fac-similada da edição princeps, de 1717).

DEROUET, B. Dot et héritage: les enjeux de la chronologie de la transmission. In: . L'histoire grande ouverte. Hommages à Emmanuel Le Roy Ladurie. Réunis sous la direction d'André Burguière, Joseph Goy et Marie-Jeanne Tits-Dieuaide. Paris: Fayard, 1997. p. 284-292.

FRIGO, D. Il padre di famiglia. Governo della casa e governo civile nella tradizione dell "economica" tra Cinque e Seicento, "Biblioteca del Cinquecento, 29". Roma: Bulzoni Editore, 1985. p. 65-101.

Disciplina rei familiariae: a economia como modelo administrativo de Ancien Régime. Penélope. Fazer e Desfazer a História, n. 6, p. 47-62, 1991. 
FLANDRIN, J.-L. Famílias. Parentesco, casa e sexualidade na sociedade antiga. Lisboa: Estampa, 1992. p. 19 (edição original: 1976; edição revista: 1984).

FRUTUOSO, G. Livro quarto das saudades da Terra. 2. ed. Ponta Delgada: Instituto Cultural de Ponta Delgada, 1977. p. 4. v. 1.

GUIGNET, P. Le pouvoir dans la ville au XVIII e siècle: pratiques politiques, notabilité et éthique sociale de part et d'autre de la frontière franco-belge. Paris: École des Hautes Études en Sciences Sociales, 1990. (Civilisations et sociétés, 80), p. 317.

GIMENO SANFELIU, M. J. Patrimonio, parentesco y poder (Castelló, siglos XVI-XIX). Castelló de la Plana: Publicacions de la Universitat Jaume I, 1998. (Biblioteca de les aules, 7), p. 139.

HUFTON, O. Mulheres, trabalho e família. In: DUBY, G.; PERROT, M. (Dir.). História das mulheres no Ocidente: do Renascimento à Idade Moderna. Sob a direção de Natalie Zemon Davis e Arlette Farge. Porto: Afrontamento, 1994. p. 23. v. 3. (Edição original: 1991).

KLAPISCH-ZUBER, C. L'invention du passé familial e Le travail généalogique. In: . La maison et le nom. Stratégies et rituels dans l'Italie de la Renaissance. Paris: École des Hautes Études en Sciences Sociales, 1990. (Civilisations et sociétés, 81), p. $19-35$ e $37-58$.

MACEDO, A. M. da C. Família, sociedade e estratégias de poder (1750-1830). A Família Jácome de Vasconcelos da Freguesia de S. Tiago da Cividade Braga, 1992. Dissertação (Mestrado em História das Populações) - Universidade do Minho.

MALDONADO, Pe. L. M. Fenix Angrence: transcrição e notas de Helder Fernando Parreira de Sousa Lima. Angra do Heroísmo: Instituto Histórico da Ilha Terceira, 1997. p. 16-91. 3. v.

MARINHO, J. da S. Construction d'un gouvernement municipal. Élites, élections et pouvoir à Guimarães entre absolutisme et libéralisme (1753-1834). Braga: Universidade do Minho, 2000. p. 238-243.

MARTÍNEZ RUEDA, F. Poder local y oligarquías en el País Vasco: las estrategias del grupo dominante en la comunidad tradicional. In: BEUNZA, J. M. I. (dir.). Elites, poder y red social: las élites del País Vasco y Navarra en la Edad Moderna. Bilbao: Servicio Editorial, Universidad del País Vasco/EHU, 1996. p. 119-146. Maxime, p. 131-142.

MONTEIRO, N. G. Casa e linhagem: o vocabulário aristocrático em Portugal nos séculos XVII e XVIII. Penélope. Fazer e Desfazer a História, n. 12, p. 43-63, 1993.

. Elites locais e mobilidade social em Portugal nos finais do Antigo Regime. Análise Social, v. 32, n. 141, p. 335-368, jul./dez. 1997. Maxime p. 363-367. 
. Poderes municipais e elites locais (séculos XVII-XIX): Estado de uma Questão. In: SEMINÁRIO INTERNACIONAL HISTÓRIA DO MUNICIPALISMO, 1., 1998, Funchal. Anais... Funchal: Centro de Estudos de História do Atlântico, Secretaria Regional do Turismo e Cultura, 1998. p. 79-89. Maxime p. 83-85.

. O crepúsculo dos grandes. A casa e o património da aristocracia em Portugal (1750-1832). Análise Social, Lisboa, p. 79-97, 1998.

PROVEDORIA DOS RESÍDUOS E CAPELAS DE PONTA DELGADA BPARPD. Legados Pios. Testamento do capitão Jerónimo Tavares de Arruda, Ribeira Grande, 2 abr. 1737, m. 68, n. 599. Maxime, fls. 7-18.

ORDENAÇÕES filipinas. Edição fac-similada da edição de Cândido Mendes de Almeida, Rio de Janeiro, 1870. Lisboa: Fundação Calouste Gulbenkian, 1985.

RILEY, C. G. As luzes escondidas da modernidade em S. Miguel (uma proposta de itinerário retrospectivo). In: CONGRESSO 1. ${ }^{\circ}$ CENTENÁRIO DA AUTONOMIA DOS AÇORES, COLECÇÃO AUTONOMIA, 19. Ponta Delgada. Actas... Ponta Delgada: Jornal de Cultura, 1995. p. 159-206. v. 1. Maxime, p. 204.

RODRIGUES, J. D. São Miguel no século XVIII: casa, família e mecanismos de poder. Ponta Delgada, 2001. Tese (Doutorado em História Moderna) - Universidade dos Açores, p. 235-238. v. 1. (policopiado).

SANZ, J. A. C. Rentas y patrimonios de la nobleza valenciana en el siglo XVIII. Historia, Madrid, p. 268, 1995.

SOBRAL, J. M. Trajectos: o presente e o passado na vida de uma freguesia da beira. Análise Social, Lisboa, p. 211, 1999. 